Z. klin. Chem. u. klin. Biochem.

10. Jg. 1972, S. 3-11

\title{
Zur Analyse von Proteoglykanen
}

\author{
Von M. LIEpländer und D. Dielenberg
}
Aus der Biocbemiscben Abteilung des Facbbereiches Cbemie der Universität Regensburg und dem Max-Planck-Institut fïr experimentelle Medizin, Göttingen

(Eingegangen am 12. Mai 1971)

Herrn Professor Dr. Dr. Friedrich Tімм in Dankbarkeit und Verebrung gewidmet

Glykosaminoglykane wie Hyaluronsäure-, Chondroitin-4- und -6-sulfat-, Dermatansulfat-, Heparin- und Kcratansulfat-Peptide wurden nach einem einheitlichen Verfahren aus den entsprechenden Bindegeweben isoliert, unter gleichen Bedingungen hydrolysiert, ihre Aminosäuren, so weit möglich, quantitativ bestimmt und die Ergebnisse untereinander verglichen. Es gelang, auch nach Anwendung verschiedener Proteasen sowie Alkali, nicht, die Glykosaminoglykane vollständig von ihren Peptid- bzw. Aminosäureresten zu befreien. - Während der sauren Hydrolyse von Glykosaminoglykanpeptiden traten Aminosäureverluste auf. Testgemische, die aus hochgereinigten Hyaluronsäuren bzw. Chondroitinsulfaten und Aminosäuren bestanden, wurden sauer hydrolysiert und anschließend säulenchromatographisch quantitativ 'getrennt und analysiert. Auffallende Verluste wurden für Arginin, Glutaminsäure, Methionin und Tyrosin registriert, Cystein war nahezu vollständig zerstört worden. - Die bei den Hydrolysen auftretenden schwarzen Rückstände wurden isoliert und es konnte gezeigt werden, daß die Aminosäurenverluste nicht einfach durch selektive Adsorption an die „Huminsubstanz" oder durch eine chemische Reaktion mit deren Vorläufer erklärt werden können. - Auf den Säulendiagrammen fanden sich neben den üblichen Aminosäurenpeaks noch neue, ninhydrinpositive, bei $440 \mathrm{~nm}$ und $570 \mathrm{~nm}$ registrierte Peaks. Derartige Peaks, die besonders zahlreich im Trennbereich der basischen Aminosäuren auftraten, wurden auch nach saurer Hydrolyse von Glucosamin sowie Galaktosamin allein gefunden. Offenbar handelte es sich bei diesen unbekannten Substanzen, zum Teil jedenfalls, um Epimerisierungsprodukte der Hexosamine. Die exakte Bestimmung, zumindest der basischen Aminosäuren, wurde hierdurch z. T. empfindlich gestört. Um die Hexosamine und diese neuen Produkte aus dem Hydrolysat vor der Aminosäurenanalyse zu entfernen, ohne dabei die Aminosäuren zu beeinflussen, wurde versucht, sie mit Acetylaceton in flüchtige Chromogene umzuwandeln, was auch gelang. Nur wurden dabei die Verluste an Aminosäuren immer dann sehr groß, wenn sich im Testgemisch Neutralzucker und/oder Uronsäuren befanden. Somit scheidet dieses Verfahren für die quantitative Aminosäurenbestimmung saurer Glykosaminoglykan-Peptid-Hydrolysatc aus. -

Die Trennbedingungen für Hydrolysate von Glykosaminoglykan-Peptiden und künstliche Hexosamin-Aminosäuren-Testgemische an verschiedenen Ionenaustauschern wurden untersucht. Dabei wurde gefunden, daß in Anwesenheit sehr großer Hexosaminmengen nur die Trennung von Nutzen ist, bei der die Hexosamine auf dem Chromatogramm relativ weit hinter den aromatischen Aminosäuren erscheinen. Trennungen und quantitative Bestimmungen der Aminosäuren-Hexosamin-Hydrolysate nach dem Einsäulenverfahren gelangen im Hinblick auf die basischen Aminosäuren nicht. Sollen diese quantitativ analysiert werden, so sind langwierige Verfahren, wie man sie zur 'Trennung sog. physiologischer Gemische verwendet, erforderlich.

\section{The analysis of proteoglycans}

Glycosaminoglycans, such as the peptides of hyaluronic acid, chondroitin-4 and -6-sulphate, dermatan sulphate, heparin sulphate and keratan sulphate were isolated from the appropriate connective tissues by a uniform method, hydrolysed under the same conditions, their amino acids determined, as far as possible quantitatively, and the results compared. It was not possible to completely free the glycosaminoglycans from their peptide or amino acid residues, even with the use of proteases or alkali, whereas the acid hydrolysis of glycosaminoglycan peptides resulted in losses of amino acids. Test mixtures, consisting of highly purified hyaluronic acids or chondroitin sulphates with amino acids, were hydrolysed with acid and resolved quantitatively and analysed by column chromatography. Marked losses were noted for arginine, glutamic acid, methionine and tyrosine, and cysteine was almost completely destroyed. The black residue produced during the hydrolysis was isolated and it was shown that the loss of amino acids was not simply due to selective adsorption onto this "humin substance" or by a chemical reaction with its precursors. The column profile showed new ninhydrin positive peaks registered at $440 \mathrm{~nm}$ and $570 \mathrm{~nm}$, in addition to the usual amino acid peaks. Some peaks were especially numerous in the separation region of the basic amino acids and these were also found after the acid hydrolysis of glucosamine or galactosamine. Some of these unknown substances may be epimerisation products of the hexosamines. The exact determination, at least of the basic amino acids, was therefore subject to a marked interference. In order to remove the hexosamines and these new products from the hydrolysate before the amino acid analysis and without affecting the amino acids, they werc converted into volatile chromogens with acctylacetone. Losses of amino acids were then still very appreciable if the test mixture contained neutral sugars and/or uronic acids. This method is therefore unsuitable for the quantitative determination of amino acids in acid hydrolysates of glycosaminoglycan-peptides.

The separation conditions for hydrolysates of glycosaminoglycan-peptides and artificial hexosamine-amino acid test mixtures on different exchangers was investigated. It was found that the separation is only of use when the hexosamines appear relativcly late after the aromatic amino acids. The separation and quantitative determination of the amino-hexosamine hydrolysates by the one column method was unsuccessful with respect to the basic amino acids. The quantitative analysis of these would involve further time-consuming procedures as normally used for the resolution of physiological mixtures.

In nativer Form sind die im Bindegewebe vorkommenden Glykosaminoglykane Chondroitin-4- und Chondroitin-6-sulfat, Dermatansulfat, die Keratansulfate sowie das Heparin kovalent an Protein bzw. Polypeptide ge- bunden. $\mathrm{Ob}$ das gleiche auch für Hyaluronsäuren gilt, ist noch nicht endgültig geklärt (1).

Zur Strukturaufklärung der genannten Verbindungen ist es notwendig, genaue Uronsäure-, Hexosamin- und 
Aminosäureanalysen durchzuführen. Dabei müssen oft klcine Mengen an Aminosäuren und Neutralzucker neben sehr viel Uronsäure und Hexosamin quantitativ nachgewiesen werden. Das ist mit Hilfe der Papierchromatographie nur bedingt möglich.

Die Methode der Wahl ist die quantitative Trennung der Aminosäuren und Hexosamine an Ionenaustauschersäulen und ihre anschließende Bestimmung mit Ninhydrin (2).

\section{Analyse von Glykosaminoglykanpeptiden}

Wie schon ANDERson und Mitarbeiter (3) zeigten, traten bei der Hydrolyse von Glykosaminoglykanpeptiden Aminosäureverluste auf. Sie hydrolysierten Chondroitin6-sulfat, das durch Extraktion mit Alkali aus Knorpel isoliert und gereinigt war, zusammen mit Edestin, dessen Aminosäurenzusammensetzung sie kannten. Besonders auffallend war der Verlust an Arginin, Glutaminsäure, Prolin, Valin, Isoleucin und Tyrosin. Außerdem fanden sie zahlreiche unbekannte ninhydrinpositive Peaks, ganz gleich, ob sie Chondroitinsulfat allein oder in Gegenwart bekannter Mengen Edestin hydrolysierten. Darüberhinaus enthielten die Hydrolysate beträchtliche Mengen an Ammoniak, das offenbar durch die Zerstörung von Hexosaminen während der Hydrolyse entstanden war. Dieser hohe Ammoniakgehalt verursachte eine erhöhte Basislinie und störte gelegentlich die exakte Bestimmung der basischen Aminosäuren. Im Zusammenhang mit unseren Untersuchungen über den Aminosäurengehalt hochgereinigter Hyaluronsäuren (4) und anderer Glykosaminoglykane prüften wir ebenfalls, in welchem Ausmaß Aminosäuren bei der Hydrolyse in Gegenwart von Glykosaminoglykanen zerstört werden. Dazu wollten wir möglichst aminosäurenfreie, aber chemisch noch intakte Glykosaminoglykane herstellen, um dann deren Hydrolyrse gemeinsam mit zugesetzten, reinsten Aminosäuren durchzuführen und festzustellen, unter welchen Hydrolyse-Bedingungen die Zerstörung von Aminosäuren am besten verhindert werden könnte. Die für die hier geschilderten Versuche benötigten Glykosaminoglykane wurden nach enzymatischem Abbau der entsprechenden Gewebe mit Papain nach den im experimentellen Teil angegebenen Methoden isoliert. Versuche, die Peptide aus den Glykosaminoglykanen durch weiteren enzymatischen Abbau mit Pronase und anschließender Einwirkung von $0,5 \mathrm{~N}$ Kalilauge ( $24 \mathrm{Stdn}$. bei $4^{\circ}$ ) zu entfernen, führten zu keinem endgültigen Erfolg. So enthielt Chondroitin-4-schwefelsäure, die aus Luftröhrenknorpel vom Rind durch Abbau der Proteine mit Papain gewonnen war, nach der Hydrolyse mit $\mathrm{HCl}$ noch insgesamt $227 \mu \mathrm{Mol}$ Aminosäuren/g. Nach der Pronasebehandlung waren es noch $116 \mu \mathrm{Mol}$ Aminosäuren/g und nach Einwirkung von Kalilauge $77 \mu \mathrm{Mol}$ Aminosäuren/g. Bis dahin schien die Kohlenhydratkette chemisch noch nicht sehr stark verändert gewesen zu sein. Eine intensivere Behandlung mit Kalilauge führte jedoch zu einer nennswerten Änderung der Glykosaminoglykanstruktur (Abspaltung von Sulfat-, Acetylgruppen). Ähnliche Befunde erhielten wir mit Hyaluronsäure, auch hier waren die Peptide durch Einwirkung von Pronase und $0,5 \mathrm{~N}$ Kalilauge nicht restlos $\mathrm{zu}$ entfernen (4). Da sich also die Restpeptide aus den Glykosaminoglykanen nicht weiter entfernen ließen, wurden alle Versuche mit den in Tabelle 1 aufgeführten Glykosaminoglykan-Peptiden durchgeführt.

- Tab. 1

Bausteinanalysen einiger Glykosaminoglykan-Peptide in \%. Analysiert wurden Hyaluronsäure aus menschlicher Nabelschnur, Heparin aus Rinderlungen, Chondroitin-4-sulfat aus Rindertrachea, Dermatansulfat aus Schweinehaut, Chondroitin-6-sulfat aus dem Knorpel von Grundhai, Keratansulfat aus Rindercornea (zur Bezeichnung I und I siehe exp. Teil)

Die Glykosaminoglykane lagen alle als Natriumsalze vor. (* Galakbestimmt nach 5 stündiger Hydrolyse der Keratansulfate in $6 \mathrm{~N}$ Salzsäure)

\begin{tabular}{|c|c|c|c|c|c|c|c|}
\hline Baustein & 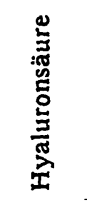 & 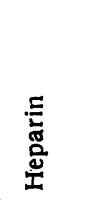 & 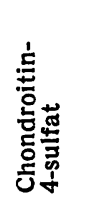 & 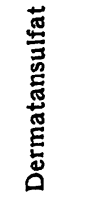 & 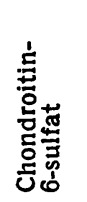 & 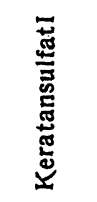 & 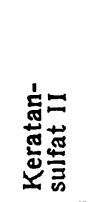 \\
\hline $\begin{array}{l}\text { Uronsäure } \\
\text { Hexosamin } \\
\text { Stickstoff } \\
\text { Schwefel }\end{array}$ & $\begin{array}{r}44,8 \\
41,3 \\
3,5 \\
\end{array}$ & $\begin{array}{r}34,1 \\
27,7 \\
2,9 \\
10,9\end{array}$ & $\begin{array}{r}35,5 \\
33,6 \\
3,1 \\
5,4\end{array}$ & $\begin{array}{r}29,1 \\
28,9 \\
3,3 \\
5,1\end{array}$ & $\begin{array}{r}36,2 \\
31,8 \\
3,1 \\
6,0\end{array}$ & $\begin{array}{c}33,6 * \\
36,7 * * \\
2,9 \\
5,6\end{array}$ & $\begin{array}{c}34,3 * \\
37,1 * * \\
3,1 \\
6,0\end{array}$ \\
\hline $\begin{array}{l}\text { Lysin } \\
\text { Histidin } \\
\text { Arginin } \\
\text { Asparaginsäure } \\
\text { Threonin } \\
\text { Serin } \\
\text { Glutaminsäure } \\
\text { Prolin } \\
\text { Glycin } \\
\text { Alanin }\end{array}$ & $\begin{array}{l}\overline{0,08} \\
\overline{0,02} \\
\overline{0,01} \\
0,02 \\
\overline{0,01}\end{array}$ & $\begin{array}{l}0,12 \\
0,05 \\
0,02 \\
0,05 \\
\overline{0,03} \\
0,02 \\
\overline{0,06} \\
0,03\end{array}$ & $\begin{array}{l}0,07 \\
0,03 \\
0,01 \\
0,19 \\
0,10 \\
0,64 \\
0,30 \\
0,17 \\
0,25 \\
0,09\end{array}$ & $\begin{array}{l}0,32 \\
0,08 \\
0,01 \\
0,29 \\
0,02 \\
0,32 \\
0,37 \\
0,08 \\
0,14 \\
0,26\end{array}$ & $\begin{array}{l}0,12 \\
0,06 \\
0,03 \\
0,13 \\
0,03 \\
0,17 \\
0,21 \\
0,22 \\
0,16 \\
0,06\end{array}$ & $\begin{array}{l}0,24 \\
0,17 \\
0,09 \\
1,04 \\
0,26 \\
0,21 \\
0,33 \\
0,11 \\
0,21 \\
0,14\end{array}$ & $\begin{array}{l}\overline{0,16} \\
0,66 \\
0,11 \\
0,22 \\
0,27 \\
0,04 \\
0,17 \\
0,10\end{array}$ \\
\hline $\begin{array}{l}\text { Cystin/2 } \\
\text { Valin }\end{array}$ & $=$ & 二 & $\overline{0,15}$ & 二 & $\overline{0,05}$ & 0,32 & 0,19 \\
\hline Methionin & - & - & - & - & - & 0,11 & 0,07 \\
\hline $\begin{array}{l}\text { Isoleucin } \\
\text { Leucin }\end{array}$ & $=$ & 二 & $\overline{0,23}$ & $\overline{0.02}$ & $\overline{0,08}$ & $\begin{array}{l}0,09 \\
0,13\end{array}$ & $\begin{array}{l}0,06 \\
0,05\end{array}$ \\
\hline $\begin{array}{l}\text { Tyrosin } \\
\text { Phenylalanin }\end{array}$ & $\underline{0,01}$ & $\underline{0,02}$ & $\begin{array}{l}0,02 \\
0,15\end{array}$ & 0,71 & $\overline{0,05}$ & $\begin{array}{l}0,10 \\
0,29\end{array}$ & $\begin{array}{l}0,01 \\
0,18\end{array}$ \\
\hline $\begin{array}{l}\text { Summe der } \\
\text { Aminosäuren }\end{array}$ & 0,15 & 0,40 & 2,40 & 2,62 & 1,37 & 3,84 & 2,29 \\
\hline
\end{tabular}

Hyaluronsäure und Chondroitin-4-sulfat hydrolysierten wir in Gegenwart eines Aminosäuren-Testgemisches mit $6 \mathrm{~N} \mathrm{HCl}$ bei $110^{\circ}$. Um einen starken Abbau der Hexosamine und Aminosäuren durch Neben- und Nachfolgereaktionen tunlichst zu vermeiden, haben wir die Proteobzw. Peptidoglykane immer in einem relativ großen Volumen Salzsäure 20-24 Stdn. hydrolysiert. Längere Hydrolysezeiten führten nur zu einer weiteren Zerstörung der Hexosamine, die Aminosäurenwerte wurden hierdurch nicht erhöht. Offenbar reichte die Hydrolysezeit aus, um alle Peptidbindungen zu spalten. Kürzere Hydrolysezeiten und geringere Salzsäurekonzentrationen waren nicht zu empfehlen, da unter diesen Bedingungen die Peptide oder Proteine nicht genügend abgebaut wurden. Hydrolysen in konzentrierteren Lösungen führten zu größeren Aminosäureverlusten. Wie Tabelle 2 zeigt, treten sowohl bei der Hydrolyse von Hyaluronsäuren als auch Chondroitinsulfaten zum Teil bemerkenswerte Aminosäurenverluste auf. Besonders auffallend waren sie für Arginin, Glutaminssäure, Methionin und Tyrosin; Cystin war nahezu ganz zerstört worden. In allen Hydrolysaten lag relativ viel Ammoniumchlorid vor, das auch hier durch Zerstörung der Hexosamine während der Hydrolyse entstanden sein dürfte. Außerdem hatten sich in den gelb bis braun gefärbten Hydrolysaten 
Tab. 2

2,5- $\mu$ Mol-Aminosäurentestgemisch (eine Lösung, die alle in der Tabelle 2,5- $\mu \mathrm{Mol}$-Aminosäurentestgemisch (eine Losung, die alle in der Tabelle aufgeführten Aminosăuren enthalt, und zwar von jeder Aminosaure

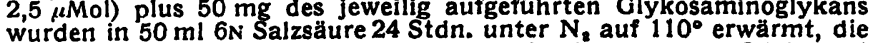
wurden in $50 \mathrm{ml}$ ( $\mathrm{N}$ Salzsaure 24 eing. unter $\mathrm{N}_{2}$ auf Lösung im Vakuum schonend eingedampft, der trockene Rückstand
in $5 \mathrm{ml}$ Citratpuffer $\mathrm{pH} 2,2$ aufgenommen und jeweils $1 \mathrm{ml}$ der Aminosäurenanalyse unterzogen. Desglelchen wurde mit den entsprechenden Glykosaminoglykanen allein verfaliren und die erhaltenen Aminosäurenwerte von der vorher bestimmten abgezogen. Die in der Tabelle
aufgeführten Werte stellen die Ausbeuten in \% dar. Der Verlust an aufgeführten Werte stellen die Ausbeuten
Cystein war groß

\begin{tabular}{lrrrrr}
\hline \multicolumn{1}{c}{ Aminosäure } & $\begin{array}{c}\text { Hyalu- } \\
\text { ron- } \\
\text { săure* }\end{array}$ & $\begin{array}{c}\text { Hyalu- } \\
\text { ron- } \\
\text { săure** }\end{array}$ & $\begin{array}{c}\text { Chon- } \\
\text { droitin- } \\
\text { 4-sulfat }\end{array}$ & $\begin{array}{c}\text { Chon- } \\
\text { droitin- } \\
6 \text {-sulfat }\end{array}$ & $\begin{array}{c}\text { Mittel- } \\
\text { wert }\end{array}$ \\
\hline Lysin & 109,4 & 111,2 & 105,7 & 104,9 & 107,8 \\
Histidin & 99,4 & 103,1 & 98,9 & 100,2 & 100,4 \\
Arginin & 87,1 & 88,7 & 84,7 & 83,3 & 85,9 \\
Asparaginsäure & 92,2 & 93,7 & 94,8 & 93,3 & 93,5 \\
Threonin & 98,2 & 94,9 & 93,2 & 94,3 & 95,1 \\
Serin & 97,8 & 98,2 & 95,7 & 94,1 & 96,4 \\
Glutaminsäure & 88,7 & 87,1 & 99,9 & 91,3 & 89,5 \\
Prolin & 97,2 & 95,9 & 94,8 & 95,6 & 95,8 \\
Glycin & 93,6 & 92,7 & 92,9 & 91,9 & 92,6 \\
Alanin & 93,1 & 94,2 & 91,4 & 93,2 & 92,9 \\
Valin & 100,2 & 102,4 & 99,2 & 99,8 & 100,4 \\
Methionin & 81,1 & 81,9 & 70,3 & 67,3 & 71,7 \\
Isoleucin & 96,5 & 97,1 & 94,9 & 95,7 & 96,0 \\
Leucin & 97,6 & 95,7 & 95,9 & 94,8 & 96,0 \\
Tyrosin & 81,1 & 77,9 & 75,2 & 78,1 & 78,0 \\
Phenylalanin & 99,2 & 104,7 & 95,8 & 96,4 & 99,0 \\
\hline
\end{tabular}

* aus Glaskörper ** aus Nabelschnur

schwarze, in $6 \mathrm{~N} \mathrm{HCl}$ unlösliche „Huminsubstanzen“" gebildet. Um festzustellen, ob Aminosäuren in nennenswertem Maße von der Huminsubstanz absorbiert werden, haben wir jeweils $30 \mathrm{mg}$ der isolierten „Huminsubstanz" in $3 \mathrm{ml}$ Aminosäurentestgemisch, das je $1,5 \mu \mathrm{Mol}$ der in Tabelle 1 aufgeführten Aminosäuren enthielt, geschüttelt, den Niederschlag scharf abzentrifugiert und im Überstand die Aminosäuren quantitativ bestimmt. Bis auf Tyrosin und Phenylalanin fanden wir alle Aminosäuren zu $100 \pm 2 \%$ wieder. Nur die Werte für Tyrosin und Phenylalanin lagen um $95 \pm 3 \%$ bzw. $93 \pm 4 \%$.

\section{Abbau der Uronsäuren und Huminbildung in starker Mineralsäure}

Während der salzsauren Hydrolyse der Glykosaminoglykan-Peptide entstanden stets schwarze Niederschläge in nennenswerter Menge. Glucuronsäure, Galakturonsäure sowie Furfurol reagierten ähnlich, wenn sie in $6 \mathrm{~N} \mathrm{HCl}$ unter Rückfluß erhitzt wurden. In jedem Fall entstand schon nach kurzer Reaktionszeit ein schwarzer Niederschlag und die Reaktionslösungen waren gelb bis braun gefärbt. Nach Ausschütteln mit Xylol konnten in der abgetrennten organischen Phase mit Anilin und Eisessig rot gefärbte Lösungen erhalten werden. Die Spektren dieser Lösungen waren gleich und ergaben ein Absorptionsmaximum bei $530 \mathrm{~nm}$. Offenbar bildeten sich intermediär Furfurol oder verwandteVerbindungen, die sofort weiter abgebaut wurden. ANDERson und Mitarbeiter (5) erhielten bei der Decarboxylierung von Uronsäuren durch Kochen in 19 proz. Salzsäure neben $\mathrm{CO}_{2}$ in geringen Mengen noch andere flüchtige Verbindungen wie Furan, Acetaldehyd und Aceton. Unter dem Einfluß starker Mineralsäuren decarboxylieren die Uronsäuren auch in Glykosaminoglykanen. Dabei sollten sich intermediär ohne oder unter gleichzeitiger Spaltung der Glykosidbindungen die den Uronsäuren entsprechenden Pentosen bilden, die dann unter dem Einfluß der Mineralsäure in Furfurol und weitere Umwandlungsprodukte übergehen. So einfach scheint der $\mathrm{Ab}$ bauweg aber nicht zu sein. Es gelang uns nicht, in salzsauren Lösungen von Glucuronsäure bzw. Galakturonsäure (in 2-6N $\mathrm{HCl}$ ), die unterschiedlich lang auf $110^{\circ}$ erhitzt waren, Pentosen wie Arabinose bzw. Xylose gaschromatographisch auch nur in Spuren nachzuweisen, selbst unter Bedingungen nicht, unter denen wir vorher zugesetzte Pentosen wiederfanden. Ähnliches galt für Hyaluronsäure und Chondroitin-6-sulfat. Bei den schwarzen „Huminrückständen“ handelt es sich aufgrund der Elementaranalysen (Tab. 3 ) um praktisch stickstoffreie Verbindungen, die sich in Natronlauge lösen und mit Säure wieder ausgefällt werden können. Dasselbe Ergebnis erhielten wir, wenn die oben genannten Verbindungen in Gegenwart zugesetzter Aminosäuren hydrolysiert wurden. Es wird demnach praktisch kein Stickstoff aus den Hexosaminen bzw. Aminosäuren in die Huminsubstanz eingebaut.

Tab. 3

Huminartige Rückstände nach 15 stündiger Hydrolyse der aufgeführten Substanzen in $6 \mathrm{~N} \mathrm{HCl}$ bei $110^{\circ}$

\begin{tabular}{lccc}
\hline \multicolumn{1}{c}{ Huminrückstand aus } & C \% & H \% & N \% \\
\hline Hyaluronsäure & 65,2 & 4,8 & 0,01 \\
Chondroitin-4-sulfat & 64,7 & 4,4 & 0,03 \\
Chondroitin-6-sulfat & 64,4 & 4,2 & 0,00 \\
D-Glucuronsäure & 64,4 & 4,3 & 0,00 \\
Furfurol & 67,5 & 4,8 & 0,00 \\
\hline
\end{tabular}

\section{Epimerisierungen}

Neben den üblichen Aminosäurepeaks treten, wie das Aminosäurenchromatogramm eines Chondroitin-4-sulfat-Peptid-Hydrolysats zeigt (Abb. 1), neue ninhydrinpositive, bei $440 \mathrm{~nm}$ und $570 \mathrm{~nm}$ registrierte Peaks auf, vor allem im Bereich vor der Asparaginsäure, zwischen Leucin und Tyrosin sowie nach dem Galaktosamin. Der letzte Peak in Abbildung 1 stellt Ammoniak dar, basische Aminosäuren werden in diesem Bereich -- nach 7-8 Stunden - nicht von der 69/0,9-Beckman-Unichrom-Säule eluiert. Im Bereich der basischen Aminosäuren traten nach Chromatographie an der 23/0,9Beckman-Unichrom-Säule neue ninhydrinpositive Peaks auf, die zum Teil im Lysin- (Keratansulfat-Hydrolysat) als auch im Histidinbereich (Hyaluronsäure-Hydrolysat) lagen. Diese Aminosäuren ließen sich daher nicht immer genau bestimmen. Mit den Hydrolysaten der übrigen in Tabelle 1 aufgeführten Glykosaminoglykan-Peptide erhielten wir auf beiden Säulen ähnliche Trennungen. Auch auf dem nach dem Biocal-Einsäulenverfahren erhaltenen Chromatogramm eines Hyaluronsäure-Hydrolysates (Abb. 2) fanden wir im Bereich zwischen Glucosamin und Ammoniak einige neue ninhydrinpositive Substanzen; auf dem Chromatogramm eines Chondroitin-4-sulfat-Hydrolysats (Abb.3) erschienen sie zum Teil erst hinter dem Ammoniakgipfel. Beim Erhitzen eines Gemisches aus gleichen Teilen Glucuronsäure und Glucosamin in $6 \mathrm{~N} \mathrm{HCl}$ unter Stickstoff auf $110^{\circ}$, entstanden neben viel Ammoniak noch andere ninhydrinpositive Substanzen, deren Lage auf dem Chromato- 

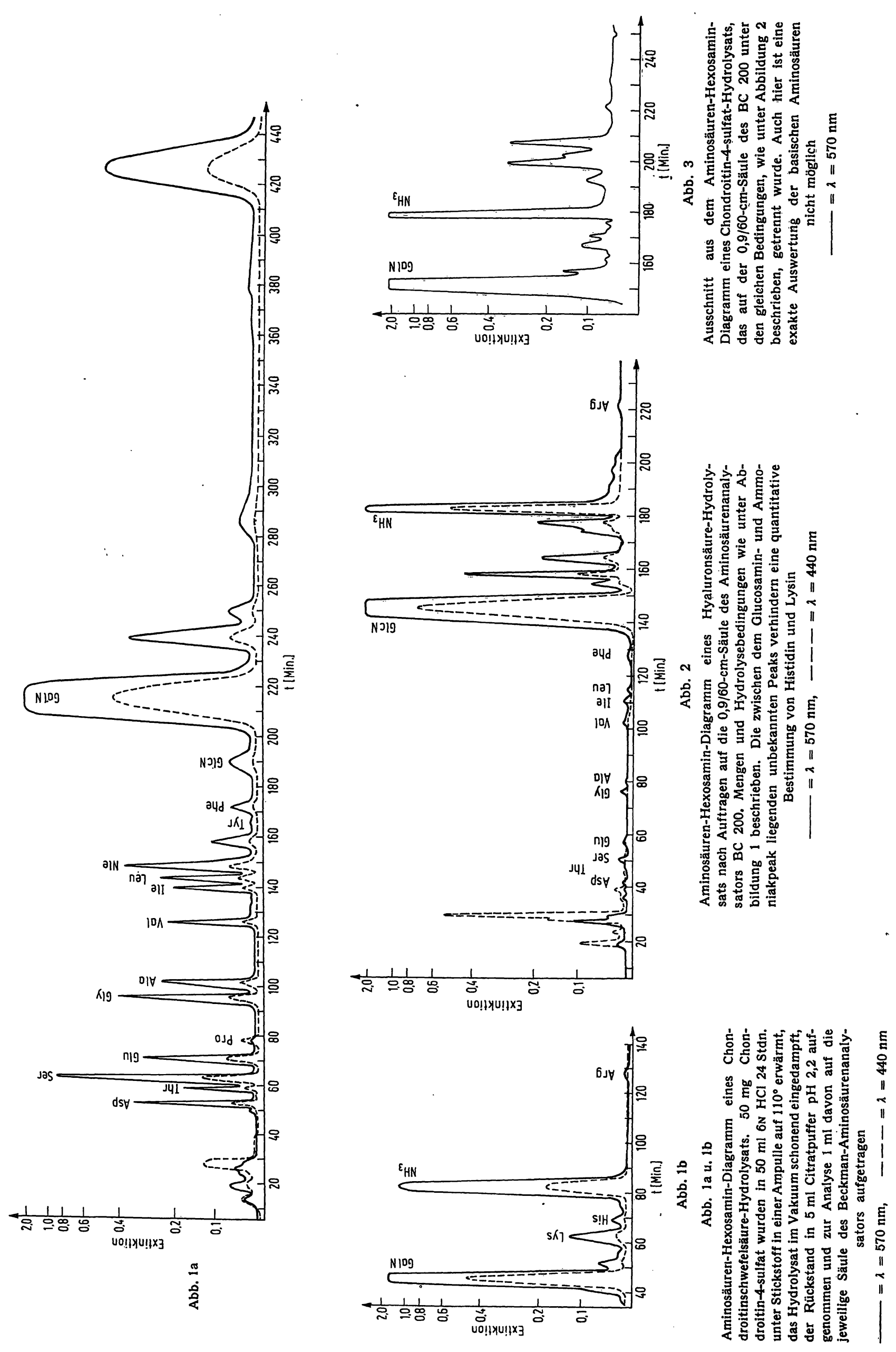

Z. klin. Chem. u. klin. Biochem. / 10. Jahrg. 1972/ Heft 1 
Abb. 4

$10 \mathrm{mg}$ reinstes Glucosamin- $\mathrm{HCl}$ und 10 $\mathrm{mg}$ Glucuronsäure wurden in $50 \mathrm{ml} 6 \mathrm{~N}$ $\mathrm{HCl} 24$ Stdn. unter Stickstoff in eine Ampulle auf $110^{\circ}$ erhitzt, die Lösung im Vakuum schonend eingedampft, der Rückstand in $2 \mathrm{ml}$ Citratpuffer aufgenommen und $1 \mathrm{ml}$ auf die $0,9 / 60-\mathrm{cm}$ Säule des BC 200 aufgetragen. Das Diagramm weist am Anfang einen Peak auf, der sowohl bei $440 \mathrm{~nm}$ als auch $570 \mathrm{~nm}$ registriert wurde. Zwischen dem Glucosamin- und dem Ammoniakpeak treten zahlreiche neue ninhydrinpositive Substanzen auf, ebenfalls hinte dem Ammoniakpeak. Nicht mit Salzsäure behandeltes Glucosamin- $\mathrm{HCl}$ ergab nur einen einzelnen, symmetrischen Peak

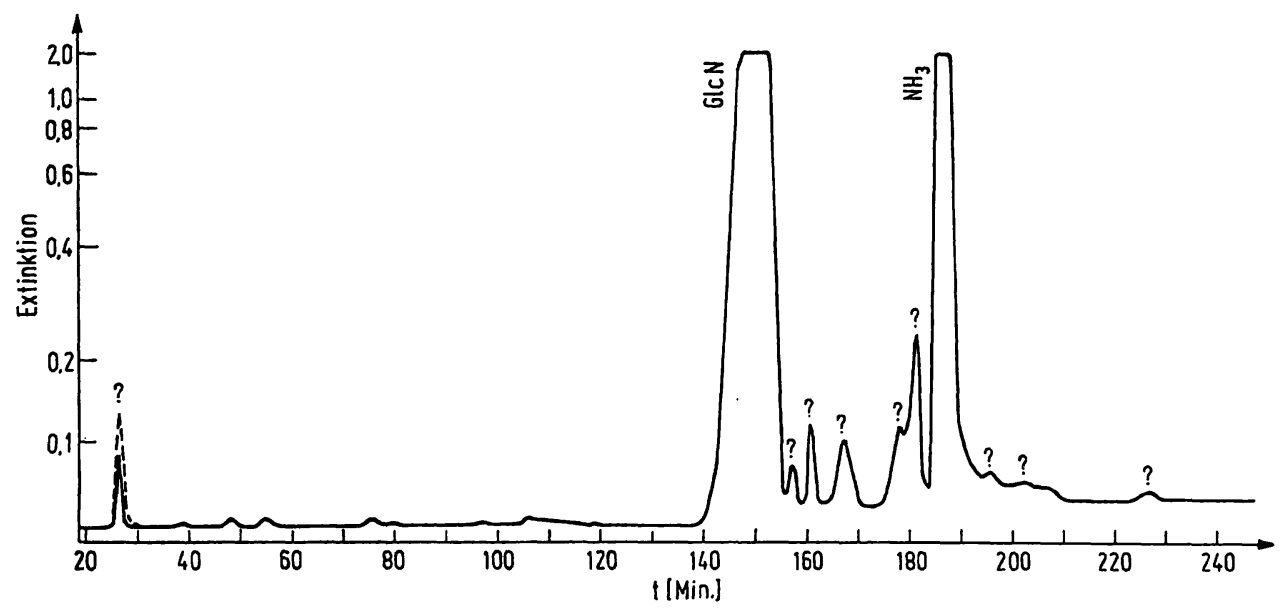

gramm (Abb. 4) derjenigen der unbekannten ninhydrinpositiven Substanzen des Hyaluronsäure- bzw. Chondroitinschwefelsäure-Hydrolysats entsprach (siehe Abb. 2 und 3).

Welcher Art die neugebildeten ninhydrinpositiven Substanzen sind, wissen wir noch nicht. Da sie aber, jedenfalls zum Teil, durch Behandlung mit Acetylaceton in Pyridinpuffer $\mathrm{pH}$ 9,5 in Chromogene umgewandelt werden konnten, ist $z u$ vermuten, $\mathrm{da} \beta$ es sich bei der einen oder anderen neugebildeten Substanz um einen von Glucosamin und Galaktosamin verschiedenen Aminozucker handelt. Diese Vermutungen werden durch einen Befund von Murr (6) unterstützt, die in einem Chondroitinsulfat-Hydrolysat, besonders nach längerer Einwirkung von 2-6N Salzsäure, einen neuen Aminozucker fand. Nach papierchromatographischer Trennung von Glucosamin und Galaktosamin ergab dieser durch Abbau mit Ninhydrin eine Pentose, die in ihrem chromatographischen Verhalten nicht von Lyxose unterschieden werden konnte. MuIR schloß daher auf Talosamin, das Epimere des Galaktosamins. Offenbar hatte während der Hydrolyse u. a. eine Epimerisierung des Galaktosamins stattgefunden.

\section{Entfernung der Hexosamine und ihrer Umwand- lungsprodukte durch Chromogenbildung mit Acetylaceton}

Die Umwandlungsprodukte der Hexosamine stören somit, zumindest bei der Aminosäurenchromatographie an einer einzigen Ionenaustaụchersäule (Einsäulenverfahren) die Bestimmung der basischen Aminosäuren, die in Glykosaminoglykan-Peptid-Hydrolysaten neben großen Mengen an Hexosaminen nur in geringer Menge vorliegen. Um diesen Schwierigkeiten zu entgehen, stellten wit uns die Aufgabe, die Hexosamine und ihre Umwandlungsprodukte durch Chromogenbildung mit Acetylaceton in flüchtige oder nicht mehr mit Ninhydrin reagierende Derivate umzuwandeln, ohne daß dabei die Aminosäuren in Mitleidenschaft gezogen würden.

Erhitzt man Hexosamine in alkalischem Milieu mit Acetylaceton, so erhält man Chromogene, die in saurer Lösung mit $p$-Dimethylaminobenzaldehyd violette bis purpurrote Färbungen ergeben. SchLoss (7) fraktio- nierte diese Chromogene und erhielt neben einer Flüssigkeit mehrere feste Substanzen, die er aber nicht näher charakterisierte. Aus einem Elson-MorgaN-Reaktionsgemisch (8) destillierten CORNFORTH und FirTh (9) 2-Methyl-pyrrol und isolierten aus dem Rückstand 2-Methyl-3-acetyl-pyrrol. Es war nach diesen Befunden und nach Arbeiten von Cessi und PiLIEgo (10) anzunehmen, daß auch nach Erhitzen eines HexosaminAminosäuren-Gemisches mit Acetylaceton in alkalischem Milieu die Hexosamine quantitativ in Chromogen umgewandelt und wenigstens zum Teil abdestilliert werden könnten. Darüber hinaus hofften wir, daß die nichtflüchtigen Chromogene nicht mit Ninhydrin reagieren und somit auch nicht die Bestimmung der Aminosäuren stören würden.

Aminosäurentestgemische wurden deshalb gemeinsam mit größeren Mengen (etwa $10 \mu \mathrm{Mol}$ ) Glucosamin und Galaktosamin in einem Pyridinpuffer $\mathrm{pH}$ 9,5 eine Stunde lang in Gegenwart von Acetylaceton auf dem Dampfbad erhitzt und das Reaktionsgemisch anschließend im Vakuum bis zur Trockene eingedampft. Den Rückstand lösten wir in Wasser und entnahmen der Lösung aliquote Teile zur Aminosäurenanalyse. Wir konnten auf diese Weise die Hexosamine so weit entfernen, daß sie die Bestimmung der Aminosäuren nicht mehr störten. Die Umwandlungsprodukte der Hexosamine ergaben im gesamten Aminosäuren-Diagramm keine störenden ninhydrinpositiven Peaks, noch gingen sie mit den Aminosäuren selbst in wesentlichem Umfang auf Kosten letzterer ein (siehe Tab. 4, Spalte 1).

Um das Verhalten des Hexosamin-Aminosäuren-Gemisches unter den Bedingungen einer salzsäuren Hydrolyse zu prüfen, haben wir das Testgemisch 20 Stunden lang in $\sigma_{\mathrm{N}} \mathrm{HCl}$ auf $110^{\circ}$ erhitzt, das ,Hydrolysat" im Vakuum zur Trockene eingedampft und den Rückstand mit Acetylaceton behandelt. Tryptophan wurde zerstört. Auch Methionin und Cystein unterlagen einem partiellen Abbau. Cysteinsäure und Methioninsulfon entstanden nur in geringer Menge. Sie konnten den Verlust an schwefelhaltigen Aminosäuren nicht ausgleichen. Alle übrigen Aminosäuren fanden wir innerhalb der zugelassenen Fehlergrenze quantitativ wieder (Tabelle 4, Spalte 2). Die Hexosamine waren im Chromatogramm nicht mehr nachzuweisen. Fügte man den Aminosäuren- 
Tab. 4

Übersicht über die in Gegenwart von Glucosamin, Glucuronsäure bzw. Galaktose durchgeführten Aminosäureanalysen (n $=4$ ) und deren Fehler. Spalte 1: $\dot{\mathbf{X}}=$ wiedergefundene Aminosäuremenge in $\mu \mathrm{g}$

Spalte 1: 2,5 $\mu \mathrm{Mo}$ Aminosaurents dampft, der trockene Rückstand in 5 mi Citratpuffer pH 2,2 aufgenommen und jeweils 1 ml der Aminosäurenanalyse unterzogen (BeckmanUnichrom-Aminosäurenanalysator).

Spalte 2:

"Hydrolysen" wie unter 1. Nach Eindampfen des Hydrolysats im Vakuum wurde der trockene Rückstand in Pyridinpuffer pH 9,5 mit Acetylaceton behandelt (siehe exp. Teil), das Lösungsmittel abdestilliert und der Rückstand in 5 ml Citratpuffer pH 2,2 aufgenommen. Analyse wie unter 1 .

Spalte 3:

Wie unter 3, nur hier wiederum Aufnalıme des trockenen Hydrolyserückstandes in Pyridinpuffer pH 9,5 und anschließende Behandlung mit Acetylaceton. Aufarbeitung und Analyse wie unter 2.

Spalte 5:

Wie unter 3 , nur anstelle von $10 \mu \mathrm{Mol}$ Glucuronsäure $10 \mu \mathrm{Mol}$ Galaktose im Testgemisch.

Spalte 6:

Wie unter 5, nur daß der Hydrolysenrückstand vor der Analyse mit Acetylaceton in Pyridinpuffer pH 9,5 behandelt wurde.

\begin{tabular}{|c|c|c|c|c|c|c|c|c|c|c|}
\hline \multirow[b]{2}{*}{ Aminosäure } & \multirow{2}{*}{$\begin{array}{c}\text { Einge- } \\
\text { setzte } \\
\text { Menge } \\
(\mu \mathrm{g})\end{array}$} & \multicolumn{3}{|c|}{1} & \multicolumn{3}{|c|}{2} & \multicolumn{3}{|c|}{3} \\
\hline & & $\overline{\mathbf{x}}$ & $\mathbf{s}$ & Fehler \% & $\overline{\mathbf{x}}$ & $\mathbf{s}$ & Fehler \% & $\overline{\mathbf{x}}$ & $\mathbf{s}$ & Fehler $\%$ \\
\hline $\begin{array}{l}\text { Lysin } \\
\text { Histidin } \\
\text { Arginin } \\
\text { Asparaginsäure } \\
\text { Threonin } \\
\text { Serin } \\
\text { Glutaminsäure } \\
\text { Prolin } \\
\text { Glycin } \\
\text { Alanin } \\
\text { Cystin/2 } \\
\text { Valin } \\
\text { Methionin } \\
\text { Isoleucin } \\
\text { Leucin } \\
\text { Tyrosin } \\
\text { Phenylalanin }\end{array}$ & $\begin{array}{l}73,1 \\
77,6 \\
87,1 \\
66,5 \\
59,5 \\
52,5 \\
73,5 \\
57,5 \\
37,5 \\
44,5 \\
60,0 \\
58,5 \\
74,6 \\
65,6 \\
65,6 \\
90,6 \\
82,6\end{array}$ & $\begin{array}{l}73,2 \\
77,5 \\
86,3 \\
66,7 \\
59,3 \\
51,8 \\
74,9 \\
58,9 \\
37,5 \\
44,9 \\
46,2 \\
59,2 \\
60,6 \\
65,8 \\
65,4 \\
90,7 \\
84,4\end{array}$ & $\begin{array}{l}1,15 \\
0,62 \\
1,75 \\
1,18 \\
0,51 \\
0,95 \\
1,24 \\
1,01 \\
0,48 \\
0,56 \\
1,05 \\
0,98 \\
1,68 \\
0,38 \\
0,76 \\
0,81 \\
0,54\end{array}$ & $\begin{array}{l}+0,13 \\
-0,13 \\
+0,92 \\
+0,30 \\
-0,34 \\
-1,33 \\
+1,90 \\
+2,43 \\
+0,27 \\
+0,90 \\
-23,00 \\
+1,19 \\
-18,76 \\
+0,30 \\
+0,30 \\
+0,11 \\
+2,17\end{array}$ & $\begin{array}{l}71,2 \\
76,4 \\
83,3 \\
66,4 \\
58,1 \\
51,9 \\
72,8 \\
57,6 \\
37,6 \\
43,9 \\
32,8 \\
57,5 \\
45,2 \\
64,2 \\
63,5 \\
89,6 \\
82,3\end{array}$ & $\begin{array}{l}1,11 \\
1,17 \\
1,17 \\
0,47 \\
0,68 \\
0,26 \\
0,22 \\
0,41 \\
0,35 \\
0,34 \\
0,81 \\
0,39 \\
0,87 \\
0,51 \\
0,65 \\
0,64 \\
0,68\end{array}$ & $\begin{array}{l}-2,60 \\
-1,50 \\
-7,80 \\
-0,15 \\
-2,35 \\
-0,95 \\
-0,95 \\
+0,17 \\
+0,27 \\
-1,34 \\
-45,30 \\
-1,70 \\
-39,41 \\
-2,13 \\
-3,20 \\
-1,00 \\
-0,36\end{array}$ & $\begin{array}{l}74,1 \\
77,9 \\
85,0 \\
67,6 \\
59,5 \\
52,3 \\
74,3 \\
57,5 \\
37,6 \\
44,5 \\
40,6 \\
57,6 \\
56,8 \\
66,1 \\
63,7 \\
87,2 \\
81,6\end{array}$ & $\begin{array}{l}0,55 \\
0,43 \\
0,67 \\
0,38 \\
0,37 \\
0,43 \\
0,38 \\
0,41 \\
0,44 \\
0,35 \\
0,47 \\
0,29 \\
0,41 \\
0,25 \\
0,37 \\
0,41 \\
0,26\end{array}$ & $\begin{array}{l}+1,37 \\
+0,39 \\
-8,15 \\
+1,65 \\
\pm 0 \\
-0,38 \\
+1,07 \\
\pm 0 \\
+0,27 \\
\pm 0 \\
-32,30 \\
-1,56 \\
-23,86 \\
+0,76 \\
-2,90 \\
-3,75 \\
-1,21\end{array}$ \\
\hline
\end{tabular}

\begin{tabular}{|c|c|c|c|c|c|c|c|c|c|}
\hline & \multicolumn{3}{|c|}{4} & \multicolumn{3}{|c|}{5} & \multicolumn{3}{|c|}{6} \\
\hline & $\overline{\mathbf{x}}$ & $\mathbf{s}$ & Fehler \% & $\overline{\mathbf{x}}$ & $\mathbf{s}$ & Fehler \% & $\overline{\mathbf{x}}$ & $\mathbf{s}$ & Fehler $\%$ \\
\hline $\begin{array}{l}\text { Lysin } \\
\text { Histidin } \\
\text { Arginin } \\
\text { Asparaginsäure } \\
\text { Threonin } \\
\text { Serin } \\
\text { Glutaminsäure } \\
\text { Prolin } \\
\text { Glycin } \\
\text { Alanin } \\
\text { Cystin/2 } \\
\text { Valin } \\
\text { Methionin } \\
\text { Isoleucin } \\
\text { Leucin } \\
\text { Tyrosin } \\
\text { Phenylalanin }\end{array}$ & $\begin{array}{l}62,1 \\
66,1 \\
67,2 \\
60,7 \\
53,2 \\
47,8 \\
62,2 \\
51,5 \\
33,4 \\
40,8 \\
15,7 \\
52,4 \\
14,5 \\
59,8 \\
56,6 \\
76,4 \\
71,7\end{array}$ & $\begin{array}{l}1,00 \\
1,16 \\
2,65 \\
0,52 \\
0,69 \\
0,56 \\
1,09 \\
1,42 \\
0,46 \\
0,86 \\
3,90 \\
1,62 \\
2,92 \\
2,02 \\
1,30 \\
1,29 \\
0,54\end{array}$ & $\begin{array}{l}-15,05 \\
-14,82 \\
-22,85 \\
-8,72 \\
-10,59 \\
-8,95 \\
-15,37 \\
-10,43 \\
-10,93 \\
-8,31 \\
-73,83 \\
-10,43 \\
-80,56 \\
-8,84 \\
-13,72 \\
-15,67 \\
-13,20\end{array}$ & $\begin{array}{l}74,9 \\
76,5 \\
84,7 \\
66,2 \\
58,3 \\
51,9 \\
70,8 \\
56,5 \\
37,5 \\
44,1 \\
33,1 \\
57,1 \\
18,5 \\
66,5 \\
65,4 \\
86,8 \\
79,5\end{array}$ & $\begin{array}{l}0,78 \\
0,49 \\
0,52 \\
0,39 \\
0,31 \\
0,28 \\
0,39 \\
0,26 \\
0,29 \\
0,35 \\
0,59 \\
0,47 \\
0,56 \\
0,46 \\
0,38 \\
0,51 \\
0,49\end{array}$ & $\begin{array}{l}+2,60 \\
+144 \\
-2,76 \\
-0,45 \\
-2,02 \\
-0,95 \\
-3,67 \\
-1,74 \\
\pm 0 \\
-0,90 \\
-46,50 \\
-2,39 \\
-75,20 \\
+1,37 \\
-0,30 \\
-4,20 \\
-3,76\end{array}$ & $\begin{array}{l}63,9 \\
50,5 \\
66,6 \\
61,1 \\
52,9 \\
50,8 \\
57,9 \\
51,8 \\
32,9 \\
41,2 \\
16,0 \\
52,5 \\
18,4 \\
64,2 \\
58,9 \\
75,6 \\
69,5\end{array}$ & $\begin{array}{l}0,41 \\
0,55 \\
0,46 \\
0,61 \\
0,33 \\
0,59 \\
0,37 \\
0,22 \\
0,33 \\
0,57 \\
2,20 \\
0,37 \\
1,35 \\
0,40 \\
0,42 \\
0,37 \\
0,42\end{array}$ & $\begin{array}{l}-12,44 \\
-34,92 \\
-23,53 \\
-8,01 \\
-10,92 \\
-3,23 \\
-21,22 \\
-9,91 \\
-12,26 \\
-7,41 \\
-73,30 \\
-10,25 \\
-75,32 \\
-2,13 \\
-10,21 \\
-16,55 \\
-15,86\end{array}$ \\
\hline
\end{tabular}

testgemischen außer Hexosamin noch Glucuronsäure zu, so erhielt man nach 20-stündiger Hydrolyse ebenfalls bis auf Methionin, Cystein und Tryptophan alle Aminosäuren quantitativ zurück (Tabelle 4, Spalte 3). Erst nach Behandlung solcher „Hydrolysate" mit Acetylaceton in Pyridinpuffer pH 9,5 traten starke Aminosäurenverluste auf (Tabelle 4, Spalte 4). Mit Galaktose anstelle von Glucuronsäure ergab sich ein ähnliches Bild (Tabelle 4, Spalte 5 und 6). Die Hexosamine waren nach der Behandlung der Testgemische mit Acetylaceton bei $\mathrm{pH}$ 9,5 nicht mehr auf dem Chromatogramm nachweisbar. Im Zusammenhang mit den eben genannten Aminosäurenverlusten sind Befunde von CESSI und PILIEGO (10) interessant, die Aminosäuren zusammen mit Glucose der Reaktion mit Acetylaceton in alkalischer Lösung unterwarfen. Sie erhielten in den meisten Fällen nach Zugabe einer salzsauren Lösung von $p$-Dimethylaminobenzaldehyd purpurrot gefärbte Lösungen mit einem Absorptionsmaximum bei $530 \mathrm{~nm}$. Lysin ergab hierbei den höchsten, Tryptophan den niedrigsten Wert. Wir konnten ähnliche Befunde mit Galaktose, Mannose und Glucuronsäure erheben. Erhitzen wir die Kohlenhydrate mit den entsprechenden Aminosäuren zuvor einige Stunden in GN $\mathrm{HCl}$ auf $110^{\circ}$, so ergab die im Vakuum schonend bis zur Trockene eingedampfte Lösung einen dunkelbraunen Rückstand, der, in Wasser gelöst, die genannte Reaktion mit Acetylaceton/p-Dimethylaminobenzaldehyd nicht mehr ergab. Es ist demnach nicht möglich, den Verlust an Aminosäuren nach Behandlung der Hydrolysate mit Acetylaceton bei pH 9,5 auf die Bildụng ElSON-MORGaN-positiver Substanzen zurückzuführen. Um außer an Testgemischen die Methode auch an Natur- 
stoffen zu studieren, haben wir neben Chitin noch die in Tabelle 1 aufgeführten Glykosaminoglykan-Peptide zusammen mit Aminosäurentestgemischen 24 Stunden lang in $6 \mathrm{~N} \mathrm{HCl}$ unter Stickstoff auf $110^{\circ}$ erhitzt, das $\mathrm{Hy}$ drolysat eingedampft und aliquote Teile direkt bzw. erst nach Behandlung mit Acetylaceton analysiert. Wie Tabelle 5 zeigt, treten größere Aminosäurenverluste nach Behandlung mit Acetylaceton in Pyridinpuffer $\mathrm{pH}$ 9,5, bei all den Substanzen auf, die Uronsāure bzw. Galaktose enthalten, während die Aminosäuren, die zusammen mit Chitin hydrolysiert wurden, in annehmbaren Mengen zurückerhalten wurden. In Abbildung 5 haben wir die

Tab. 5

Jeweils $50 \mathrm{mg}$ Glykosaminoglykan wurden zusammen mit $5 \mu \mathrm{Mol}$ Aminosäurentestgemisch (vgl. Tab. 1,1) in $50 \mathrm{ml} 6 \mathrm{~N}$ Salzsäure $24 \mathrm{Stdn}$ unter Stickstoff auf $110^{\circ}$ erhitzt, das Hydrolysat im Vakuum schonend zur Trockene eingedampft und der Rückstand in $10 \mathrm{ml}$ Wasser auf genommen. Jeweils $4 \mathrm{ml}$ wurden in Kölbchen pipettiert und wiederum bis zur Trockene eingedampft. Der neue Rückstand wurde zur Analyse gleich in $5 \mathrm{ml}$ Citratpuffer $\mathrm{pH} \mathrm{2,2}$ aufgenommen, der andere mit Acetylaceton in Pyridinpuffer $\mathrm{pH} \mathrm{9,5}$ behandelt (vgl. exp. Teil) Diese Lösung wurde ebenfalls im Vakuum bis zur Trockene eingedampft und der Rückstand in $5 \mathrm{ml}$ Citratpuffer pH 2,2 zur Analyse gelëst. In den einzelnen Spalten sind die Aminosäureverluste in Prozent nach Behandlung der Hydrolysate mit Acetylaceton aufgeführt

Hier wurden $25 \mathrm{mg}$ Chitin mit $5 \mu \mathrm{Mol}$ Aminosäurentestgemisch hydrolysiert. Aufarbeitung und Analysen wie beschrieben

\begin{tabular}{|c|c|c|c|c|c|c|}
\hline Aminosäure & $\begin{array}{l}\text { Hyalu- } \\
\text { ron- } \\
\text { säure }\end{array}$ & $\begin{array}{l}\text { Chon- } \\
\text { droitin- } \\
\text { 4-sul- } \\
\text { fat }\end{array}$ & $\begin{array}{l}\text { Chon- } \\
\text { droitin- } \\
\text { 6-sul- } \\
\text { fat }\end{array}$ & Heparin & $\begin{array}{c}\text { Kera- } \\
\text { tan- } \\
\text { sulfat }\end{array}$ & Chitin \\
\hline $\begin{array}{l}\text { Lysin } \\
\text { Histidin } \\
\text { Arginin } \\
\text { Asparaginsäure } \\
\text { Threonin } \\
\text { Serin } \\
\text { Glutaminsäure } \\
\text { Prolin } \\
\text { Glycin } \\
\text { Alanin } \\
\text { Cystin/2 } \\
\text { Valin } \\
\text { Methionin } \\
\text { Isoleucin } \\
\text { Leucin } \\
\text { Tyrosin } \\
\text { Phenylalanin } \\
\text { Tryptophan }\end{array}$ & $\begin{array}{l}39,96 \\
34,84 \\
32,34 \\
33,16 \\
30,06 \\
28,05 \\
34,15 \\
63,35 \\
30,88 \\
27,67 \\
59,51 \\
29,72 \\
32,73 \\
30,63 \\
32,05 \\
28,89 \\
26,75 \\
-\end{array}$ & $\begin{array}{l}48,62 \\
38,38 \\
46,91 \\
25,25 \\
21,29 \\
22,83 \\
41,63 \\
58,91 \\
25,89 \\
16,20 \\
81,33 \\
15,62 \\
21,16 \\
13,63 \\
19,17 \\
24,08 \\
18,98 \\
-\end{array}$ & $\begin{array}{l}46,09 \\
47,67 \\
46,95 \\
30,86 \\
34,74 \\
32,66 \\
43,56 \\
86,15 \\
38,19 \\
34,50 \\
70,33 \\
2751 \\
41,56 \\
32,17 \\
35,99 \\
30,68 \\
20,06 \\
\end{array}$ & $\begin{array}{r}44,04 \\
35,19 \\
37,12 \\
40,39 \\
34,44 \\
36,11 \\
41,68 \\
69,42 \\
12,06 \\
7,55 \\
66,13 \\
15,25 \\
30,56 \\
22,85 \\
27,15 \\
28,55 \\
28,71\end{array}$ & $\begin{array}{r}15,30 \\
12,88 \\
17,91 \\
7,91 \\
5,78 \\
2,11 \\
8,23 \\
25,80 \\
8,60 \\
2,53 \\
44,65 \\
10,63 \\
64,40 \\
8,63 \\
10,73 \\
6,63 \\
8,95 \\
\end{array}$ & $\begin{array}{r}2,9 \\
3,1 \\
3,9 \\
1,0 \\
4,3 \\
3,9 \\
4,8 \\
4,7 \\
3,0 \\
1,8 \\
18,2 \\
2,8 \\
17,3 \\
3,1 \\
3,9 \\
2,1 \\
3,4 \\
\end{array}$ \\
\hline
\end{tabular}

\section{Zur Trennung von Hexosaminen und Aminosäuren an Ionenaustauschersäulen}

Vor einigen Jahren gelang es uns (11), unter Verwendung einer Eingradienten-Mikrosäule, Aminosäuren, die in einem Hyaluronsäure-Hydrolysat in geringer Menge vorlagen, aufzutrennen und quantitativ zu bestimmen. Bedingt durch den hohen Glucosamingehalt war es jedoch nicht möglich, den Wert für Leucin und Tyrosin exakt zu ermittcln, da der zwischen Leucin und Tyrosin erscheinende Glucosamingipfel die genannten Aminosäuren teilweise überdeckte. Außerdem war die quantitative Analyse der basischen Aminosäuren aus den oben genannten Gründen problematisch. Das gleiche galt auch bei der Analyse dieses Hydrolysats an Amberlite CG 120 und IRC-50 in einer Apparatur nach HANNIG (12), sowie an Aminex-6-Ionenaustauschharz nach dem Einsäulenverfahren mit dem Biocal-BC-200 und an PA 28- und PA 35-Ionenaustauscherharzen nach dem Zweisäulenverfahren mit dem Beckman-Unichrom-Gerät. Da jedoch die Trennfolge der Hexosamine dank ihrer besonderen ionischen Struktur durch eine Änderung des $\mathrm{pH}$ Bereichs zwischen 3,25 und 4,25 nicht stark beeinflußt wird - was für Aminosäuren nicht gilt -, konnten wir die aromatischen Aminosäuren durch zeitliche Änderung des Pufferwechsels von den Hexosaminen trennen. Dabei erschienen je nach Art des Pufferwechsels die Hexosamine entweder vor, $z$ wischen oder hinter den aromatischen

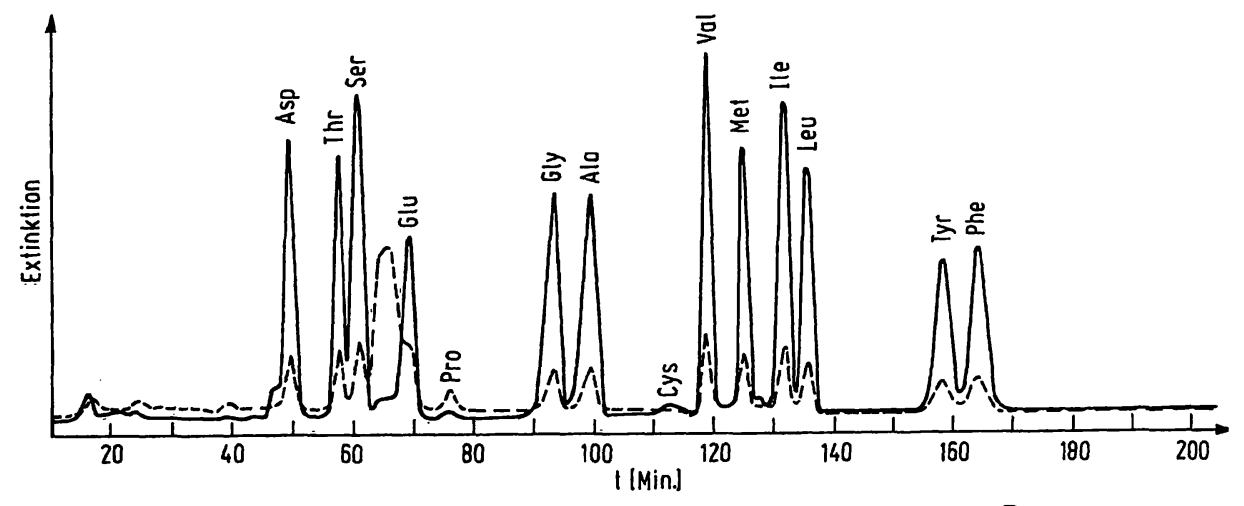

Abb. 5a u. 5b

Aminosäuren-Hexosamin-Diagramm eines Chondroitin-4-sulfat/AminosäurenHydrolysats. $50 \mathrm{mg}$ Chondroitin-4-sulfat wurden zusammen mit einem 2,5 $\mu$ Mol-Aminosäuren-Testgemisch (vgl. Tab. 2) in $50 \mathrm{ml} 6 \mathrm{~N} \mathrm{HCl}$ unter Stickstoff $24 \mathrm{Stdn}$. auf $110^{\circ}$ erhitzt, das Hydrolysat im Vakuum schonend eingedampft, der Rückstand mit Acetylaceton in wäßrigem Pyridin behandelt, die Lösung im Vakuum eingedampft und der Rückstand in $5 \mathrm{ml}$ Citratpuffer pH 2,2 aufgenommen. Jeweils $1 \mathrm{ml}$ wurde auf die entsprechende Säule des Beckman-Geräts aufgetragen

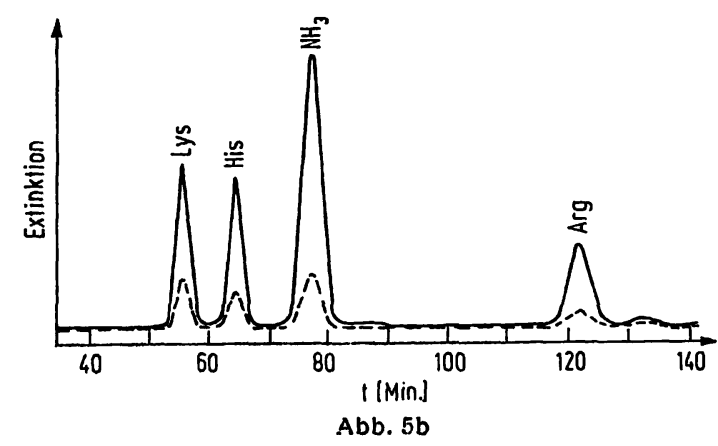


Aminosäuren. Die besten Trennungen, vor allem wenn große Mengen Hexosamine neben geringen Mengen Aminosäuren vorlagen, waren die, bei denen die Hexosamine hinter den aromatischen Aminosäuren erschienen. Wie die vorliegenden Untersuchungen weiter zeigen, entstehen bei der Hydrolyse der GlykosaminoglykanPeptide aus den Hexosaminen ninhydrinpositive Abbauprodukte, die die quantitative Bestimmung der basischen Aminosäuren stören. Sie können zwar durch Chromogenbildung entfernt werden, dadurch tritt aber ein größerer Aminosäurenverlust auf. Deshalb versagte in unserem Fall die Analyse der GlykosaminoglykanPeptid-Hydrolysate nach dem substanz- und zeitsparenden Einsäulenverfahren ganz. Nur wenn wir nach dem Zweisäulenverfahren und dann bei den basischen Aminosäuren unter Verwendung von Methoden, die der Auftrennung sogenannter physiologischer Aminosäurengemische dienen, arbeiteten, gelang es uns, die basischen Aminosäuren von den Hexosaminen und ihren Abbauprodukten so zu trennen, daß eine quantitative Bestimmung der basischen Aminosäuren möglich war. Bei diesen Verfahren, die im Durchschnitt etwa 6 Stunden dauerten, kamen die basischen Aminosäuren Lysin, Histidin, Arginin nach, die Hexosamine vor dem Ammoniakpeak.

\section{Material und Methoden}

\section{Material}

L-Aminosäuren, D-Glucosamin- $\mathrm{HCl}$, Galaktosamin- $\mathrm{HCl}$ und Glucuronsäure waren analysenreine Präparate. - Chitin wurde aus Krebsschalen nach HACKMAN (13) dargestellt (Ber. N 6,89 für $\left(\mathrm{C}_{8} \mathrm{H}_{13} \mathrm{NO}_{5}\right)_{n}(203,2$ für $\mathrm{n}=1)$; gef. N 6,69\%). - Glycosaminoglykan-Peptide haben wir aus menschlicher Nabelschnur, aus Rinderglaskörper, Rinder-Tracheaknorpel, Schweinehaut und Grundhaiknorpel nach Abbau der Gewebe mit Papain (14) isoliert und im präparativen $\mathrm{MaBstab}$ durch Chromatographie an DEAE-Sephadex- (15) und Ecteola-Cellulose-Säulen (16) gereinigt. $\mathrm{Da}$ so nur eine Trennung in eine Hyaluronsäure-, eine Chondroitinsulfat/Dermatansulfat/Keratansulfat- und eine $\mathrm{He}$ parin-Fraktion möglich war, wurden die chromatographisch abgetrennten Glykosaminoglykan-Peptid-Gemische noch aus einer 5proz. Calciumacetatlösung in $0,5 \mathrm{~N}$ Essigsäure durch $\mathrm{Zu}-$ gabe von Äthanol bis zu einer jeweils bestimmten Alkoholkonzentration fraktioniert gefällt (17). Die Dermatansulfatfraktion wurde anschließend noch mit Hyaluronidase (18) behandelt. Zur Reindarstellung von Keratansulfat haben wir Rinder-Corneae mit Papain abgebaut und das Keratansulfat in Anlehnung an eine Vorschrift von K. MEYER und Mitarbeiter (17) isoliert. Nach Chromatographie an Ecteola-Cellulose nach Grexling und Mitarbeiter (19) erhielten wir 2 Hauptfraktionen I und II. - Die Analysen der Glykosaminoglykan-Peptide sind in Tabelle 1 entbalten. - Chondroitin-4-sulfat, das laut Tabelle 1 rund $227 \mu \mathrm{Mol}$ Aminosäuren pro Gramm Trockengewicht enthielt, wurde mit Pronase (20) behandelt, das Enzym mit Trichloressigsäure ausgefällt, der Uberstand nach Neutralisation mit $\mathrm{NaOH}$ dialysiert, an DEAE-Sephadex chromatographiert, dialysiert, mit Dowex X 8 (100-200 mesh, $\mathrm{H}^{+}-$Form) entsalzt und gefriergetrocknet. Die Analysen ergaben: Gesamtmenge an Aminosäuren $116 \mu \mathrm{Mol} / \mathrm{g}$ Trockengewicht; Aminosäurengesamtstickstoff 0,18\%; Gesamtstickstoff 3,06\%; Gesamtschwefel 5,99\%; Acetylgruppen 12,50\%; Uronsäure $37,8 \%$; Hexosamin 36,4\%. 1 g dieser Substanz wurde in das Kaliumsalz überführt, in $500 \mathrm{ml} 0,5 \mathrm{~N} \mathrm{KOH}$ gelöst und $24 \mathrm{Stdn}$. bei $4^{\circ}$ aufbewahrt. Nach Neutralisation mit Eisessig, Dialyse gegen dest. Wasser und Entsalzen mit Dowex X 8 wurde die Lösung gefriergetrocknet. Wir erhielten ein farbloses Produkt, das sich nach einigen Tagen, auch im Exsikkator über $\mathrm{P}_{2} \mathrm{O}_{5}$, gelb färbte. Analysen: Gesamtmenge an Aminosäuren $77 \mu \mathrm{Mol} / \mathrm{g}$ Trockengewicht; Aminosäurengesamtstickstoff 0,11\%; Gesamtstickstoff 2,91\%; Gesamtschwefel 6,19\%; Acetylgruppen 11,98\%; Uronsäure $38,1 \%$, Hexosamin $37,1 \%$.

\section{Methoden}

C, H, N und S wurden wie l. c. (11) beschrieben quantitativ bestimmt, $\mathrm{N}$ außerdem noch mit Hilfe der Ultramikro-KJELDAHLNessLER-Methode (21), die Acetylgruppen nach 1. c. (22), Uronsäuren nach 1. c. (23), Hexosen nach 1. c. (24). Die quantitativen Hexosaminanalysen wurden nach CESsr und Pirrego (10) sowie mit Hilfe der Ionenaustauscherchromatographie durchgeführt. Dazu wurden stets etwa $10 \mathrm{mg}$ des jeweiligen Glykosamino-

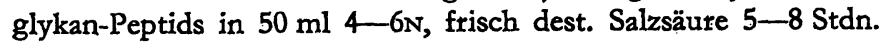
unter Stickstoff in zugeschmolzenen Ampullen auf $110^{\circ}$ erwärmt, das Hydrolysat schonend im Vakuum eingedampft, der Rückstand in den entsprechenden Puffern gelöst und aliquote Teile zur quantitativen Analyse verwandt. Zur quantitativen Analyse der Aminosäuren wurden jeweils etwa $50 \mathrm{mg}$ des Glykosaminoglykan-Peptids in $50 \mathrm{ml} 6 \mathrm{~N} \mathrm{HCl}$ unter den eben genannten Bedingungen 24 Stdn. hydrolysiert und aufgearbeitet. Die Hexosamin- und Aminosäurenanalysen wurden mit Hilfe eines automatischen BIOCAL-Aminosäurenanalysators BC 200 (Baujahr 1968) an einer $0,9 / 60 \mathrm{~cm}$-Säule mit BIORAD-Aminex A 6Ionenaustauscherharz getrennt und mit Ninhydrin nach 1. c. (25) quantitativ bestimmt. Das Pufferprogramm lief in der Reihenfolge:

a) Citratpuffer $\mathrm{pH} 3,25 \pm 0,02$, der noch $4 \%$ Äthanol enthielt (0. bis 62. Minute);

b) Citratpuffer $\mathrm{pH} 4,24 \pm 0,02$ (62. bis 125. Minute);

c) Citratpuffer $\mathrm{pH} 6,45 \pm 0,02$ (125. bis 235. Minute).

Die Natriumkonzentration aller Puffer war $0,2 \mathrm{~N}$, die Durchflußgeschwindigkeit der Puffer betrug $90 \mathrm{ml} / \mathrm{Std}$., die des Ninhydrinreagenzes $45 \mathrm{ml} / \mathrm{Std}$. Als Waschnatronlauge wurde eine $0,4 \mathrm{~N}$ Lösung (von der 235. bis zur 260. Minute) verwandt. Die Säulentemperatur betrug $53^{\circ}$. Die Trennung und quantitative Bestimmung eines Aminosäuren-Hexosamin-Gemisches dauerte hiernach etwa $4 \mathrm{Stdn}$. Leider war die quantitative Bestimmung der basischen Aminosäuren in Glykosaminoglykan-PeptidHydrolysaten nach dem Einsäulenverfahren nicht möglich. Die Trennung der basischen Aminosäuren, der Hexosamine und ihrer Abbauprodukte war unter folgenden Bedingungen möglich:

a) $0,9 / 40 \mathrm{~cm}$ Säule; Harzhöhe $25 \mathrm{~cm}$; Harz Bio Rad Aminex A 5; Elutionsmittel Natriumcitratpuffer pH 4,26 $\pm 0,02,0,38 \mathrm{~N} \mathrm{Na} \mathrm{Na}^{+}$ (0. bis 185. Minute, $\mathrm{T}=30^{\circ}$ ); Natriumcitratpuffer $\mathrm{pH} 5,28 \pm 0,02$, $0,35 \mathrm{~N} \mathrm{Na}^{+}\left(185\right.$. bis 330 . Minute, $\left.\mathrm{T}=55^{\circ}\right) ; 0,2 \mathrm{~N} \mathrm{NaOH}(330$. bis 350. Minute, $\mathrm{T}=55^{\circ}$ ); Natriumcitratpuffer $\mathrm{pH} 4,26$ wie oben (350. bis 380 . Minute, $\mathrm{T}=30^{\circ}$ ); Durchflußgeschwindigkeit der Puffer $60 \mathrm{ml} / \mathrm{Std}$., des Ninhydrins $30 \mathrm{ml} / \mathrm{Std}$.

b) $0,9 / 40 \mathrm{~cm}$ Säule; Harzhöhe $25 \mathrm{~cm}$; Harz Bio Rad Aminex 6; Elutionsmittel Natriumcitratpuffer $\mathrm{pH} 4,30 \pm 0,02,0,3 \mathrm{~N} \mathrm{Na}$, $\mathrm{T}=50^{\circ}$; Durchflußgeschwindigkeit des Puffers $68 \mathrm{ml} / \mathrm{Std}$., Ninhydrin $34 \mathrm{ml} / \mathrm{Std}$. Dauer der beiden Analysen jeweils 5-6 Stdn. Nach etwa 5 Stdn. erschien der Argininpeak.

Zur Trennung der sauren und neutralen Aminosäuren sowie der Hexosamine mit dem Beckman-Aminosäurenanalysator Unichrom (Baujahr 1967) wurde in einer 0,9/69 cm Säule Ionenaustauscherharz vom Typ PA 28 in einer Füllhöhe von $56 \mathrm{~cm}$ benutzt. Die Puffer waren in der 0 . bis 85 . Minute $0,2 \mathrm{~N}$ Natriumcitratpuffer $\mathrm{pH} \mathrm{3,28} \pm 0,02$, in der 85 . bis 240 . Minute $0,2 \mathrm{~N}$ Natriumcitratpuffer $\mathrm{pH} 4,25 \pm 0,02$. Zur Trennung der basischen Aminosäuren und Hexosamine wurde eine $0,9 / 23 \mathrm{~cm}$ Säule verwandt, die das Harz PA 35 in einer Höhe von $20 \mathrm{~cm}$ enthielt. $0,35 \mathrm{~N}$ Natriumcitratpuffer pH $5,28 \pm 0,02$ wurde als Elutionsmittel verwandt. Die Durchflußgeschwindigkeit beider Puffer betrug $68 \mathrm{ml} / \mathrm{Std}$., die des Ninhydrins $34 \mathrm{ml} / \mathrm{Std}$., die Säulentemperatur betrug $55^{\circ}$. Eine vollständige Analyse an beiden Säulen dauerte insgesamt 7--8 Stdn. Hydroxyprolinanalysen wurden in einem 
äquivalenten Teil des jeweiligen Hydrolysats nach STEGEManN (26) durchgeführt. Zum Nachweis von Pentosen wurde die Glykosaminoglykan-Peptid-Hydrolysate schonend im Vakuum eingedampft und nach KMM und Mitarbeiter (27) aufgearbeitet. Die Neutralzucker wurden nach SwEeLY und Mitarbeiter (28) in die Trimethylsilylderivate umgewandelt und gaschromatographisch nachgewiesen.

\section{Chromogenbildung und Aminosäurenanalysen:}

a) Acetylaceton-Reagenz: $1 \mathrm{ml}$ frisch dest. Acetylaceton (Kp. $\left.138-140^{\circ}\right)$ wurde in $100 \mathrm{ml}$ Pyridin/Wasser $(9: 1)$ gelöst. Der pH-Wert betrug 9,5. Die Lösung wurde vor jedem Versuch frisch hergestellt.

b) Durchführung: Jeweils $50 \mathrm{mg}$ der in Tabelle 3 aufgeführten Glykosaminoglykane wurden in $50 \mathrm{ml} \mathrm{6} \mathrm{N} \mathrm{HCl} 24 \mathrm{Stdn}$. unter
Stickstoff in abgeschmolzenen Ampullen auf $110^{\circ}$ erhitzt, das Hydrolysat im Vakuum schonend zur Trockene eingedampft und der Rückstand in $10 \mathrm{ml}$ Wasser aufgenommen. Jeweils $4 \mathrm{ml}$ wurden in Kölbchen pipettiert und bis zur Trockene im Vakuum eingedampft. Den einen Rückstand nahm man gleich zur Aminosäurenanalyse in $5 \mathrm{ml}$ Citratpuffer $\mathrm{pH} 2,20$ auf, den anderen löste man in $40 \mathrm{ml}$ Acetylacetonreagenz (entsprechend $20 \mathrm{ml}$ Acetylacetonreagenz pro $\mu \mathrm{Mol}$ Aminosäurentestgemisch; dieses Gemisch enthielt von jeder der in Tabelle 3 aufgeführten Aminosäure $1 \mu \mathrm{Mol}$ ). Diese Lösung wurde $60 \mathrm{Min}$. auf dem siedenden Wasserbad erhitzt, im Vakuum schonend eingedampft, der trokkene Rückstand in Wasser gelöst, noch einmal im Vakuum bis zur Trockene eingedampft, der Rückstand in $5 \mathrm{ml}$ Citratpuffer pH 2,20 gelöst und aliquote Teile zur Aminosäurenanalyse entnommen.

\section{Literatur}

1. Balazs, E. A., Editor, "Chemistry and Molecular Biology of the Intercellular Matrix“, Vol. 2, Academic Press, London und New York (1970). - 2. SteEle, R. S., K. Brended, E. Scheer und R. W. WheEt, Analytic. Biochem. 34, 206 (1970). - 3. Anderson, B., P. Hofrman und K. MeYer, J. biol. Chemistry 240, 156 (1965). - 4. Liefländer, M., in: E. A. Balazs, „Chemistry and Molecular Biology of the Intercellular Matrix“, Vol. 2, Seite 749, Academic Press, London und New York (1970). 5. Anderson, D. M. W., S. Garbutt und S. S. H. Zaidi, Analyt. Chim. Acta 29, 39 (1963). - 6. Murr, H., Biochem. J. 65, 33P (1957). - 7. Schloss, B., Analyt. Chemie 23, 1321 (1960). 8. Elson, L. A. und W. T. J. MORGAN, Biochem. J. 27, 1824 (1933). - 9. Cornforth, J. W. und M. E. Firth, J. Chem. Soc. (London) 1958, 1091. - 10. Cessr, C. und F. Piliggo, Biochem. J. 77, 508 (1960). - 11. LIEFLäNDER, M. und K. Thomas, HoppeSeylers Z. physiol. Chem. 342, 228 (1965). - 12. HaNnig, K., Clin. chim. Acta (Amsterdam) 4, 51 (1959). - 13. Hackman, - R. H., Austral. J. Biol. Sci. 7, 168 (1954). - 14. BudDECKE, E., Hoppe-Seyler's Z. physiol. Chem. 318, 33 (1960). - 15. Scrmidr,
M., Biochem. biophysica Acta, (Amsterdam) 63, 346 (1962). 16. Ringertz, N. R. und P. Reicharo, Acta chem. scand. 13 , 1467 (1959). - 17. MeYer, K., E. Davidson, A. Linker und P. Hopfman, Biochim. biophysica Acta, (Amsterdam) 21, 506 (1956). - 18. Cipfonelir, J. A. und L. Roden, in W. E. M. Lands, Ed. i. Ch., „Biochemical Preparations“ 12, 5 (1968). 19. Greiling, H., Th. Herbertz und H. W. Stuhlsatz, HoppeSeylers Z. physiol. Chem. 336, 149 (1964). - 20. Anderson, B., P. Hoffman und K. MeYer, J. biol. Chemistry 240, 156 (1965). 21. Strauch, L., diese Z. 3, 165 (1965). - 22. KunN, R. und H. Rorr, Chem. Ber. 66, 1274 (1933). - 23. BITTER, T. und H. MurR, Analytic Biochem. 4, 330 (1962). - 24. DreYwood, R., Ind. Engng. Chem. anal. Edit. 18, 499 (1947). - 25. SPACKMAN, D. H., W. H. Stern und S. Moore, Analytic. Chem. 30, 1190 (1958). - 26. Stegemann, H., Hoppe-Seylers Z. physiol. Chem. 311, 41 (1958). - 27. KIM, J. H., T. H. Shone, B. LiaO und J. G. Pierce, Analytic. Biochem. 20, 258 (1967). - 18. Sweely, C. C., R. Bentley, M. Makita und W. W. Wells, J. Amer. chem. Soc. 85, 2497 (1963). 